\title{
Paul Israel Singer
}

\author{
ALFREDO COSTA-FILHO
}

A AVALIAÇÃO DAS contribuições de Paul Singer à economia política e à análise econômica no Brasil fica dificultada pela extensão e diversidade da sua obra. Facilita-a seu sentido de coerência e alguma concentração em temas da economia marxista, da urbanização, do trabalho e emprego ou de demografia e saúde. Com exceção destes dois últimos, os demais estão considerados, embora com a certeza de que meticulosa análise de toda sua produção, teórica ou técnica, seria imprescindível para fazer-lhe melhor julgamento. Isto implicaria examinar perto de 170 títulos, distribuídos ao longo de aproximadamente 40 anos (1).

Economista de origem, doutor em sociologia e livre-docente em demografia, Singer publicou seus primeiros trabalhos reunindo estas três vertentes do saber em torno a temas que lhe tocava tratar como técnico ou como professor universitário.

Preocupações dominantes com a práxis e com a pedagogia marcariam definitivamente seus aportes à análise econômica. Urbanização, população, desenvolvimento e formação do mercado interno, trabalho e emprego em economias capitalistas não-desenvolvidas, fixação de salários como função de movimentos do capital, estrutura de classes e modos de produção no Brasil, além de ciclos de conjuntura, foram alguns dos seus temas mais freqüentados.

Nos limites deste artigo é impraticável qualquer análise tema a tema. No que segue, este texto estará dividido em quatro grandes blocos, em ordem nãonecessariamente histórica. No primeiro se insinua, apenas, a longa tradição ortodoxa de Singer, repassando-se alguns de seus argumentos centrais sobre desenvolvimento, urbanização, trabalho/emprego, planejamento, Estado e mercado. Mera amostra, parcial e certamente arbitrária, de alguns conceitos que facilitam o entendimento do que se trata a seguir. No segundo bloco, ilustra-se sua percepção do socialismo real e são destacadas suas críticas àquela experiência histórica. $\mathrm{O}$ terceiro está reservado às suas reflexões mais atuais, centradas na economia solidária. O último reúne algumas conclusões gerais.

\section{A raiz ortodoxa}

Seguindo a Marx, as diferenças de desenvolvimento entre os países explicamse pela teoria do imperialismo. "Entre o Setor de Mercado Externo, refletindo a penetração capitalista e o Setor de Subsistência, pré-capitalista, se espreme um pequeno Setor de Mercado Interno, que representa o embrião do capitalismo nacional" (Singer, 1975: 156-158). 


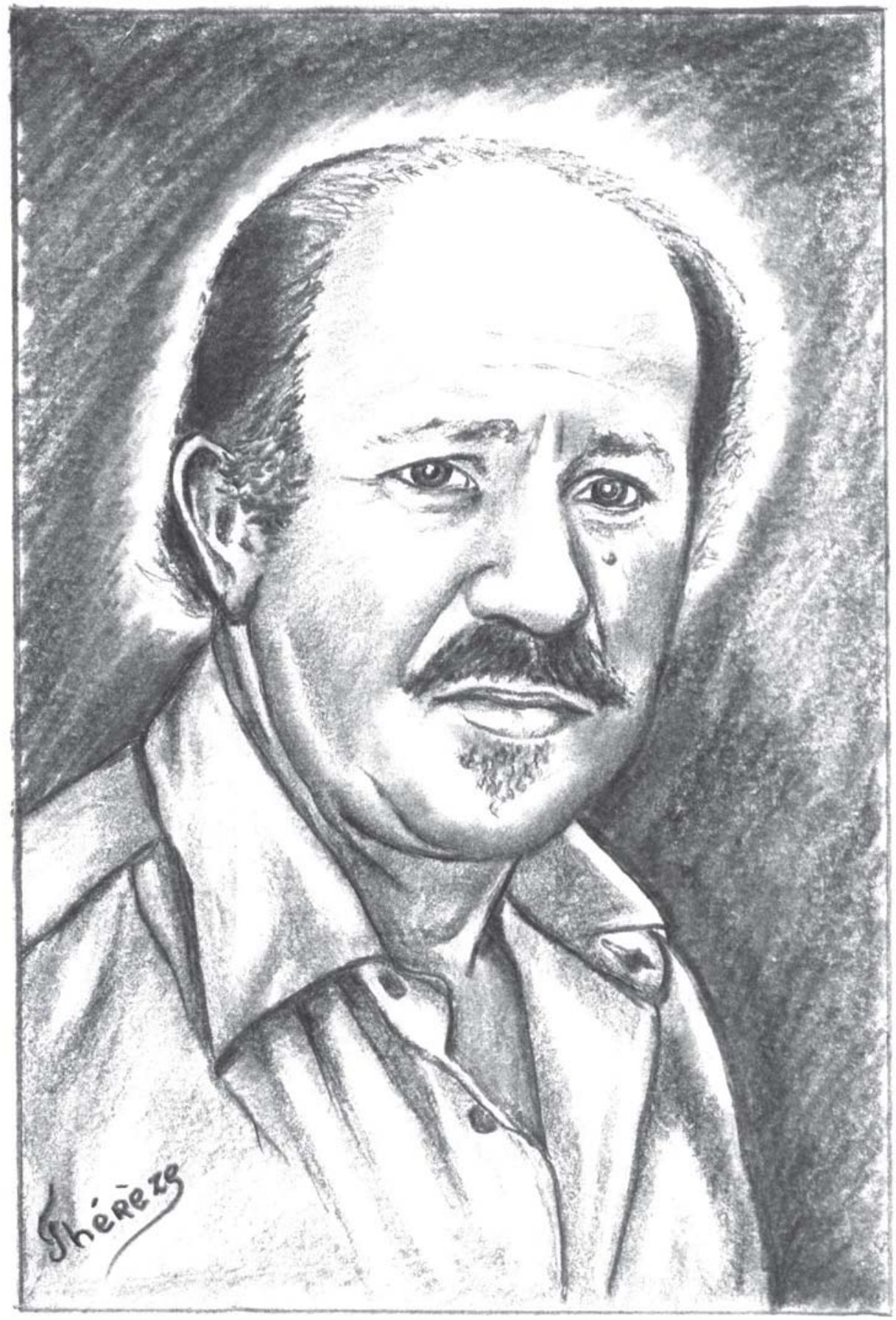

Paul Israel Singer 
Embora os incentivos constituam um problema grave da atividade produtiva, há fortes indícios, em algumas economias socialistas, de que "a capacidade de avanço e de desenvolvimento das forças produtivas ... [permita] vencer o retardo econômico no espaço de uma geração" (id.: 167-176).

Uma sociedade humana alcança o estágio de civilização urbana "quando a produção e captura do excedente alimentar permite a uma parte da população viver aglomerada e dedicar-se a outras atividades que não a produção de alimentos. ... As relações entre as classes moldam a evolução da sociedade ... estabelecendo a bipolaridade cidade-campo apenas um efeito secundário, por assim dizer 'superestrutural' daquele processo básico" (Singer, 1998a: 7-8). Assim, "a constituição da cidade é, ao mesmo tempo, uma inovação da técnica da dominação e na organização da produção". A transformação da cidade em centro de produção só pode resultar de uma luta de classes. "Neste processo, parte do mais-produto, que ainda continua vindo à luz como valor de uso, transforma-se na mão de uma nova classe dominante em valor de troca, em mercadoria. É com base nesta transformação que a cidade se insere na divisão social do trabalho, alterando-a pela base" (id.: 12-14).

A oferta de trabalho não é simplesmente daqueles que, estando em idade de trabalhar, necessitam ou desejam fazê-lo mas daqueles que, "não tendo capital ou trabalho próprio, são obrigados a tentar vender sua capacidade de trabalho" (Singer, 1977b: 183) (2). Carece de sentido, portanto, uma teoria geral do emprego com pretensões à validade para todos os modos de produção. "Nos países nãodesenvolvidos, o capitalismo é o modo de produção dominante mas consideráveis parcelas da população estão ainda inseridas em outros modos de produção". Já que a oferta de força de trabalho não resulta apenas da dinâmica populacional, mas "do movimento da população entre modos de produção, ... uma Teoria do Emprego, que pretenda dar conta do que ocorre em economias não-desenvolvidas, tem que partir da análise desta dinâmica" (id.: 4-5) (3).

Similar linha de raciocínio reaparecerá, como ver-se-á, na base das propostas mais recentes de Singer sobre economia solidária. Já sustentava que "se necessita de 'ocupação', que não é sinônimo de emprego: ... ocupação é toda atividade que proporciona sustento a quem a exerce (Singer, 1998b: 14). Em texto posterior, revela alguma desconfiança (ortodoxa) com relação às perspectivas futuras: "o socialismo autogestionário, construído dentro de sociedades capitalistas, tem poucas possibilidades de provocar transformação estrutural da economia inclusiva. A economia socialista dificilmente será alcançada por meio do mero crescimento da economia solidária" (Singer, 2000b: 44).

Certa desconfiança que se revela também com relação à possibilidade de se planejar dentro do capitalismo. "O 'planejamento' só tem sentido se é para contrariar a tendência espontânea do mercado". As experiências de êxito de planejamento capitalista, sempre autoritárias, foram experiências de tempo de 
guerra ou de pós-guerra, ou seja, de reconstrução de destruições bélicas (4). Porém, a ortodoxia implicava uma aposta no Estado: "Um processo de desenvolvimento autônomo teria que ser realizado com participação predominante de empresas estatais (Singer, 1975: 161) (5). Sem perder de vista, com Engels, que o Estado moderno, sob qualquer forma, "é máquina essencialmente capitalista, Estado dos capitalistas, o capitalista coletivo ideal (Singer, 2000b: 14).

Por sua vez, “o 'mercado' pode ser visto como um sistema de coordenação de planos particulares, inclusive de famílias e dos governos". Cabe designar a competição de mercado como anarquia de produção porque "anarquia quer dizer ausência de poder". O mercado capitalista enquadrou o tempo pela esfera financeira: na etapa atual, "o mercado financeiro cumpre o papel que no socialismo real cabe à onipotente direção do plano", ainda que tenham arbitragens distintas (Singer, 2000b: 34-37). Convém ter presente, também, que todo sistema de incentivos, no capitalismo, se baseia na apropriação privada do excedente e da sua livre utilização, de acordo com critérios privados. Assim, as possibilidades de redistribuição de renda para baixo são extraordinariamente limitadas no capitalismo (Singer, 1981: 179) (6).

Por fim, merecem enquadramento nesta tradição de ortodoxia três outras percepções habituais neste marco doutrinário, que o futuro se encarregaria de pôr em cheque ou, pelo menos, em discussão. Primeira, a de crise iminente do capitalismo: "o desenvolvimento tecnológico está levando a uma crise mundial do capitalismo pois ele exige, para sua efetiva implantação, uma planificação provavelmente internacional da economia que, sem dúvida, é incompatível com as relações de produção capitalista" (Singer, 1975: 161). Segunda, certa desconsideração da natureza e do atual poder dos insumos de conhecimento que, alojados no fulcro do novo padrão tecnológico, provocam sentida inflexão no modo contemporâneo de produção capitalista: "a separação do trabalho manual do intelectual constitui o meio do capitalista se apropriar do processo produtivo e alienar o trabalhador do processo produtivo de valorização da produção" (Singer, 1980: 44). O que leva à terceira: "a sociedade socialista deveria encorajar jovens, trabalhadores desempregados em função do avanço tecnológico ou de outras mudanças, consumidores insatisfeitos com bens e serviços etc. a tomar a iniciativa de inventar novos produtos, novos processos de produção e lançá-los em competição com os existentes" (Singer, 2000b: 47). Ou seja, crer possível competir com as inovações, aceleradas e sofisticadas, que se geram no núcleo - altamente capitalizado - das mais capazes e poderosas corporações da economia globalizada.

\section{Crítica ao socialismo real}

As restrições de Singer ao socialismo real, antes dispersas, ganham inegáveis precisão e contundência no último qüinqüênio. Começam pelos próprios clássicos: "Marx e Engels nos legaram uma crítica profunda e penetrante do capitalismo como modo de produção mas a visão científica do socialismo deixa muito a 
desejar". Ambos teriam "caído em um reducionismo evidente ... o qual teve conseqüências quando na União Soviética se tratou de aplicar à realidade as fórmulas do socialismo cientifico". Os meios de produção foram socializados mas deles “não resultou o perecimento do 'Estado' mas o contrário, seu crescimento monstruoso" (Singer, 2000b: 11-17).

Sustenta ainda que em países do socialismo realmente existente é difícil afirmar que "exista uma sociedade sem classes, isto é, que o grau de igualdade seja máximo e nitidamente superior ao das economias capitalistas mais avançadas, não só em termos econômicos mas também em termos sociais. ... O sistema político desses países é menos democrático do que o que se alcançou em alguns países capitalistas mais avançados" (Singer, 1999: 177). A economia planejada "foi organizada ao redor de completo monolitismo do poder de decisão do Estado". Tudo, entretanto, a transformava numa 'economia de escassez' ... Só a elite estatal e partidária escapa da penúria”. E, citando a János Kornai, “as pessoas são forçadas a se ajustar, gastando o dinheiro com o que conseguem comprar, mesmo que esteja longe de ser o que prefeririam” (Singer, 2000b: 23, 28, 31).

“O 'planejamento' centralizado, que foi a marca registrada do 'socialismo' soviético, nada tem a ver com a socialização dos meios de produção. Se todos estes pertencem ao Estado, em tese, cada cidadão é proprietário dos meios de produção. Mas isso não passa de uma ficção jurídica. Na prática, o controle sobre a economia era exercido pela cúpula do Partido, que também era a cúpula do Estado. E os trabalhadores continuaram tão subordinados quanto no capitalismo" (Singer, 2000b: 77) (7).

Assim, “o 'mercado' é essencial para possibilitar ao indivíduo o direito de escolha, como trabalhador e como consumidor. 'Qual é sua importância?' - pergunta-se o autor e responde - É a garantia da liberdade individual. O desemprego é o preço que se paga por esta liberdade". Para um socialista, um mal do mercado é ser instável; outro, é tender à concentração e a produzir desigualdades inaceitáveis. A moeda, de todos os modos, é-lhe imprescindível. Embora seja certo "que incentivos monetários implicam algum grau de desigualdade econômica. Alguma desigualdade econômica é absolutamente necessária para garantir os mercados que, por sua vez, garantem a liberdade" (Singer, 1997: 35-36, 39) (8).

\section{Rumo à economia solidária}

Em seus trabalhos mais recentes Singer propugna, precisamente, por um novo projeto socialista aqui e agora. Recorda que "o capitalismo se originou da produção simples de mercadorias, negando-a ao separar a posse e o uso dos meios de produção e distribuição". Esta separação resulta do próprio funcionamento dos mercados. Ali, "os vitoriosos no jogo competitivo acabam se apoderando dos meios de produção e distribuição dos derrotados”. A economia solidária surge como modo de produção e distribuição alternativo ao capitalismo, 
"criado e recriado pelos que se encontram (ou temem ficar) marginalizados do mercado de trabalho". Reúne "o princípio da 'unidade entre posse e uso' dos meios de produção e distribuição ... com o 'princípio da socialização destes meios' [aspas da transcrição] (Singer, 2000c: 12-14).

A Revolução Russa, explica o autor, “extremou uma distinção que já havia entre duas concepções de socialismo, que até então convivíam nas mesmas organizações partidárias, sindicais e cooperativas". Uma via o socialismo como seqüência do capitalismo, em uma longa transição ao comunismo; a outra o tomava como rompimento da ditadura do capital na empresa. Aquela concepção adquiriu caráter totalitário, adotando o planejamento geral e a concentração de poder como princípios do socialismo; esta, desejava a gestão coletiva dos meios de produção, pelos produtores livremente associados. Uma visão autogestionária, aclara, que remonta a Owen, Fourier e a outros socialistas utópicos do século XIX (Singer, 2000b: 39-40) (9).

Certo remanescente de utopia é ainda evidente: "para que haja participação real dos trabalhadores na direção das empresas, é preciso quebrar o monopólio de conhecimento dos que fazem o trabalho intelectual. É preciso que cada trabalhador tenha trabalhado em todos os setores da empresa, entenda seu funcionamento e esteja a par da sua situação no mercado. Somente nestas condições terão os trabalhadores possibilidades de participar das decisões, com conhecimento de causa e assumir a responsabilidade pela condução da empresa”. Isto requer, no limite, 'que não haja mais dirigentes nem dirigidos' nas empresas ..." Em resumo, quando se diz que "o socialismo pressupõe o controle operário da produção, a idéia central é que a divisão do trabalho terá de deixar de ser hierárquica, permitindo a todos a participação, em igualdade de condições, no trabalho produtivo e nos centros de tomada de decisões" (Singer, 1999: 188-189).

"A luta pelo socialismo almeja, hoje em dia, não tanto a abolição da propriedade privada dos meios de produção ... mas a eliminação da hierarquia de mando nas unidades de produção e distribuição ( $i d . .:$ 183). A economia solidária é, nestas circunstâncias, uma criação "em processo contínuo" de trabalhadores em luta contra o capitalismo. "Ela condena no capitalismo, antes de tudo, a ditadura do capital na empresa, o poder ilimitado que o direito de propriedade proporciona ao dono dos meios de produção ...” (Singer, 2000c: 13).

Singer reitera uma de suas teses iniciais: o sistema capitalista envolve "diversos 'modos de produção'. É capitalista, porque o modo de produção capitalista é econômico e socialmente predominante". Junto a ele atuam, lado a lado: "i) trabalhadores por conta própria que formam a produção simples de mercadorias; ii) empresas públicas e privadas sem fins de lucro; iii) produção para auto-subsistência nos lares e, iv) cooperativas autogestionárias, que constituem um embrião ou 'implante' socialista” [enumeração desta transcrição] (Singer, 2000b: 47). De um modo ou de outro, prossegue em texto já citado: "a construção da economia 
solidária tem sido - paralelamente à ação sindical e partidária por direitos políticos e sociais - uma das principais formas de luta contra o capitalismo". Além de permitir ganhos aos sócios, a empresa solidária é uma criação de trabalhadores em luta contra o capitalismo. "É uma opção ao mesmo tempo econômica e políticoideológica" (Singer, 2000c: 15-21) (10).

O autor reconhece que sob os princípios da economia solidária operam empresas as mais diversas, dificultando as generalizações. Abrangem, entre outras: a) cooperativas de produção, de bens ou serviços, com diferentes dotações de capital; b) pequenas associações de trabalhadores marginalizados, que dependem de apoio externo; c) cooperativas de trabalho; d) clubes de troca; e) cooperativas de consumidores. "A extraordinária variedade de organizações que compõe o campo da economia solidária permite formular a hipótese de que ela poderá se estender a todos os campos da atividade econômica" (id.: 23). Em particular, podem receber respaldo de um sistema financeiro especifico para suas necessidades (Singer, 2000a: 151), além de constituírem, eventualmente, (f) cooperativas de crédito [enumerações da transcrição].

\section{Um balancete de contribuições}

Em conformidade com o terceiro tópico deste texto, neste último são resumidas as principais conclusões deste comentarista. Nos limites deste trabalho, é nada trivial propor alguma taxonomia para contribuições de Paul Singer ao pensamento econômico no Brasil. A trilogia sugerida a seguir é mera aproximação, à qual serão acrescentadas algumas considerações finais.

Um primeiro grupo de contribuições pode ser identificado dentro do próprio pensamento marxista no país. O método prevalecente gira em torno a releituras dos clássicos, garimpando exegeses que respaldem análises aggiornadas de fenômenos econômicos e sociais contemporâneos. Os dois primeiros capítulos (Crítica da visão clássica e centralização planejada x autogestão), de um de seus textos aqui reiteradamente mencionado ilustram, com razoável clareza, este procedimento metodológico (Singer, 2000b: 11-22). É inegável que o autor desenvolveu aportes originais neste sentido, tanto para compreensão dos modos de produção e das estruturas de classe na realidade brasileira quanto para ilustrar ou mobilizar, em outros temas, possíveis correligionários (11). Observador incansável do mundo real, poder-se-ia considerar seu aporte, neste caso, como refletindo uma ortodoxia de geometria variável, que parece se evidenciar quando são contrastadas suas obras anteriores com as mais recentes (por exemplo, Singer, 1975; 1977b, com Singer, 1999; 2000b; 2000c).

Um segundo grupo de contribuições resulta de estudos empíricos, cujas conclusões enriquecem a ciência aplicada a diferentes segmentos da realidade econômica e social do Brasil. Ainda que fundamentado em uma mesma matriz doutrinária, o método é radicalmente distinto do anterior e as conclusões vão se 
enraizando em estatísticas modalmente expressas em séries históricas (além de alguns trabalhos no campo da demografia, consultem-se, por exemplo, os citados Singer 1981; 1998b. Ainda a título de ilustração, contraste-se o método de elaboração com o do recente Singer, 2000a). Desenvolvimento econômico, mercado interno e urbanização, trabalho e emprego, distribuição de renda e ciclos de conjuntura são alguns dos campos em que seus resultados coadjuvaram pesquisas relevantes de outros autores (12).

Um terceiro grupo de contribuições refere-se à difusão do conhecimento. É um aporte - talvez não-convencional - ao pensamento econômico contemporâneo cumprir esta função de pedagogia social; um princípio de "eqüifinalidade" presente no que Singer pensa, analisa, fala ou escreve. Raro haver outro autor marxista com similar preocupação em desempenhar - obviamente dentro do seu próprio credo - esta função estratégica que De Meis designa como "decodificação do novo saber" (13). Cursos às centenas e palestras aos milhares completam este esforço educativo, com inegável traço de proselitismo, que já se revela na bibliografia até aqui acumulada (reveja-se a Nota 1). Contribuições variadas, que mantêm um sentido de generosidade social e cujo eixo passa pelos temas do trabalho, do emprego, da ocupação, do salário e da desigualdade de rendas. Dirigidas a públicos heterogêneos, suas mensagens têm um núcleo duro constituído, transparentemente, por um ideário socialista que - já se mencionou - vem se flexibilizando. $\mathrm{Na}$ medida que seu discurso - falado ou escrito - se inclina mais aos excluídos do desenvolvimento capitalista, Singer tem buscado mesclar uma entrega (invariavelmente) honesta de conhecimentos com alguma quota (tática, sempre; utópica, freqüentemente; e até ingênua, algumas vezes) de esperança. Sua pregação atual, para construção da economia solidária, oferece testemunhos desta sutil e árdua catequese (14).

Concluindo, faz sentido registrar duas últimas considerações. Primeira, que este êxito plural tem um preço e exige disciplina, para manter o predomínio de uma linguagem essencialmente despojada. A preocupação medular de Singer, com a inclusão cidadã no processo de desenvolvimento, tem elementos comuns com outros enfoques latino-americanos, sustentados por profissionais de distintas origens profissionais e variada tradição doutrinária. De Bustelo, Gurrieri, Isuani ou Minujin, na Argentina; de Carafa, Calderón ou Pérez de Castaños, na Bolívia; de Hardy e Schkolnik, no Chile; ou Guendel na Costa Rica, além de outros no Brasil e nos demais países (15). Como sociólogo, que também é, sabe que novos argumentos pró-inclusão cidadã ele encontraria em numerosos pensadores, fora deste âmbito regional. E ainda que saiba das vantagens de possíveis cross-fertilizations, Singer prefere deixá-las ao lado. Incorporá-las tornaria sua mensagem mais hermética, sobretudo para seu público-meta preferencial (16).

A última consideração é que, mesmo quem eventualmente discrepe de suas análises ou de suas propostas, provavelmente concederá que Singer enfrenta, 
com integridade, o que seu ex-companheiro de Cebrap considera como primeiro desafio da estratégia de desenvolvimento social: "uma combinação adequada entre a força propulsora da indignação moral e a sagacidade esclarecedora da razão" (17).

Notas

1 Produziu, entre 1961 e 2001, perto de 20 relatórios de pesquisas científicas além de uma centena e meia de publicações, entre livros e artigos especializados. Observe-se que esta produtividade vem crescendo: a média de 1,7 trabalho/ano das primeiras décadas passou a 7,4 nas duas seguintes, saltando a 9 no biênio 2000-2001 (até junho).

2 "O desemprego e o subemprego em países não-desenvolvidos soem ser encarados como frutos de um 'desequilíbrio' entre oferta e demanda por força de trabalho, a oferta sendo condicionada primordialmente por fatores demográficos ... e a demanda resultando de fatores econômicos (ritmo de investimentos e seleção de técnicas)". A demanda e a oferta de força de trabalho são determinadas pelo movimento de capital. "Só é emprego 'capitalista' o constituído pela venda de força de trabalho" (Singer, 1977b: 181).

3 A dinâmica fundamental de acumulação do capital é, incessantemente, "a de esgotar o exército industrial de reserva mediante a multiplicação de 'novos produtos' e reconstituílo mediante a introdução de 'mudanças de processos'” (id.: 108). Prosseguindo mais adiante, “mudanças de processo' elevam a produtividade e na medida em que o fazem reduzem a demanda por força de trabalho; 'novos produtos' aumentam o consumo e na mesma medida aumentam a demanda por força de trabalho" (id.: 182). Observese que as peculiaridades do padrão de desenvolvimento tecnológico contemporâneo tornam discutível este postulado da ortodoxia marxista. Provavelmente, esta falta de percepção prospectiva (não do autor aqui analisado em si, mas deste aspecto do próprio corpo teórico que então sustentava), seja um dos fatores que justificam a conclusão recente de Coutinho sobre a fragilidade da contribuição marxista ao pensamento econômico no Brasil (veja-se, Maurício Chalfin Coutinho, Incursões marxistas, in USP, Estudos Avançados, n. 41, p. 42, jan./abr. 2001).

4 Veja-se o comentário de Paul Singer a Stuart Holand, Novas dimensões para o planejamento, in CENDEC: Estado e Planejamento, Seminário Internacional realizado em Brasília, IPEA, 1988, p. 278-281. Holand, em sua réplica, sustenta a aplicabilidade de um planejamento negociado (por pacto), conforme o comprovam as experiências realizadas em diferentes países capitalistas da Europa (França, Itália, Reino Unido, entre outros).

5 Considerando-as um recurso sine qua non para que os países não-desenvolvidos pudessem "romper a relação de dependência do grande capital internacional. Face às alternativas, de se verem subordinadas a um Estado empresário ou ao grande capital internacional, 
as classes dominantes dos países em desenvolvimento têm preferido a segunda, ainda que esta implique manutenção do atraso relativo destes países" (Singer, 1975: 161).

6 "A maior parte do excedente ... não aparece como renda pessoal mas como ganho de capital ou valorização da propriedade. ... A renda pessoal derivada da propriedade do capital [dividendos, retiradas etc.] não deixa de ser um elemento que contribui para a crescente desigualdade da distribuição da renda” (Singer, 1981: 178).

7 “O colapso do 'socialismo realmente existente' convenceu a maioria dos marxistas que o progresso econômico e os direitos individuais não podem ser garantidos sem liberdade econômica e algum grau de competição de mercado. Isto significa que o projeto socialista tem de ser redesenhado, tendo como desafio encontrar um caminho que concilie as potencialidades de liberação do mercado competitivo com os controles institucionais que reduzam a desigualdade e a exclusão social" (Singer, 1998b: 73). Por tais convicções o autor ironizara um ano antes: "eu fui marxista e devo ser ainda em grande medida..." (Singer, 1997: 29).

8 Há mais de um quarto de século Singer já insistia na questão do incentivo: "estaria na lógica da economia planificada a repartição totalmente igual da renda ou, pelo menos, a tendência a um certo igualitarismo. Tal tendência, no entanto, parece acarretar um problema muito grave que é o do incentivo à atividade produtiva" (Singer, 1975: 176). Ao criticar recentemente o sistema de incentivos do socialismo real salienta: "de qualquer forma, é preciso um projeto socialista para aqui e agora” (Singer, 1997: 39).

9 Citando a Oskar Anweiler: "a autogestão das empresas inspirou profundo temor em Lenin de que seria empecilho à reorganização da produção e ao aumento da produtividade. Travou-se então, a partir de 1918, uma grande discussão entre partidários do planejamento centralizado e os partidários da autogestão. Tendo a liderança ostensiva de Lenin e de Trotski, os primeiros ganharam a parada" (Singer, 2000b: 19).

10 Idéia contra a qual se insurge um comentarista: o capitalismo pode exercer hegemonia sobre várias formas de produção, inclusive estas "não capitalistas', porque elas não ferem, não atingem e não disputam o grande poder que está concentrado no sistema financeiro hoje, nas chamadas empresas do conhecimento de alta tecnologia e nas grandes empresas de maneira geral". Essas pequenas produções nunca incomodaram e, portanto, podem vicejar. Entretanto, prossegue, "não consigo vislumbrar qualquer possibilidade de crescimento num grau que de fato faça jus a uma estratégia socialista, daquilo que se definiu como 'implante socialista"' [Arlindo Chinaglia, em comentário à Economia Solidária] (Singer, 2000c: 69).

11 Resultando estranho que tais aportes hajam sido omitidos em algumas antologias clássicas sobre este pensamento (por exemplo, Ricardo Bielschowsky, Pensamento econômico brasileiro: o ciclo ideológico do desenvolvimento, Brasília, IPEA, 1988). Um Dicionário recente lhe faz justiça, registrando em seu verbete que é um dos fundadores do Cebrap, um estudioso da obra de Karl Marx e que realizou várias pesquisas sobre 
a realidade brasileira (Paulo Sandroni, Novíssimo dicionário de economia, São Paulo, Best Seller, 1999).

12 Entre outras, as seguintes referências - em ordem histórica - ilustram os aportes de Paul Singer nesta segunda linha de argumentação: Juarez Brandão Lopes, Desenvolvimento e mudança social, São Paulo, CEN, 1968; Florestan Fernandes, Sociedade de classes e subdesenvolvimento, Rio de Janeiro, Zahar, 1968; Octávio Ianni, Estado e planejamento econômico no Brasil, Rio de Janeiro, Civilização Brasileira, 1971; Paulo R. Souza, Emprego, salário e pobreza, São Paulo, Hucitec/Funcamp, 1980; Guido Mantega, A economia politica brasileira, São Paulo, Polis/Vozes, 1984.

13 "Para decodificar ... é preciso inserir a informação nova em um corpo de conhecimentos previamente estabelecido, de modo a torná-la útil" (Leopoldo de Meis, Preparando o futuro: a questão da educação para a ciência e tecnologia e do avanço do conbecimento, Brasília, MCT, nov. 2000, p. 15).

14 Seu valor intelectual explica sua receptividade em ambientes de saber sofisticado, como os do Cincred (Paris, 1975); DHF (Uppsala, 1977); Sage (Londres, 1985); FILB (Roma, 1987); Prokla (Berlim, 1988); Woodrow Center (Washington, 1993); University of Texas (Austin, 1996). Sua capacidade de decodificação permite entender como mais de um milhar de pessoas ouve e aplaude sua intervenção no "Congresso Brasileiro dos Catadores de Papel e Recicláveis”, realizado em Brasília (jun. 2001), um estrato que certamente está na base da estrutura social do país.

15 Referências bibliográficas em detalhe encontram-se em Alfredo Costa-Filho, Politica de redução da pobreza na América Latina: avaliação de algumas experiências, Brasília, Pnud/Unicef, 1999.

16 Modesto, jamais aderiu ao dropping names, este exercício fácil que Pitirim Sorokim popularizou como repique de bombos mútuos: "eu te cito, tu me citas". É esta qualidade moral que o leva a escrever, porque crê faltar ao seu público, uma cartilha singela sobre um complexo tema atual, praticamente sem fontes e sem números (Singer, 2000a). Apenas inspirado em suas crenças, valendo-se de seu instrumental teórico e apoiado em sua própria capacidade analítica.

17 Vilmar Faria, Importância das estratégias inovadoras de parceria, in: Estratégias inovadoras de parcerias no combate à exclusão social, Brasília, Pnud, jan. 2000.

Referências bibliográficas

SINGER, Paul I. Desenvolvimento econômico e evolução urbana. São Paulo, Cia. Editora Nacional, 1968.

Dinâmica populacionale desenvolvimento. São Paulo, Hucitec, 1970.

Curso de introdução à economia política (Aulas no Teatro de Arena,

São Paulo, 1968). Rio de Janeiro, Forense, 1975. 
SINGER, Paul I. Desenvolvimento e crise, 2.ed. (1 ${ }^{a}$ edição em 1968). Rio de Janeiro, Paz e Terra, 1977a. Economia politica do trabalho. São Paulo, Hucitec, 1977b.

. O que é o socialismo hoje. Petrópolis, Vozes, 1980.

Terra, 1981.

Dominação e desigualdade (1. ed. em 1975). Rio de Janeiro, Paz e

Marx e mercado. In: ROCHA BARROS, A.L. et al. Ensaios críticos sobre o capitalismo e o socialismo. São Paulo, Editora A. Garibaldi, 1997.

. Economia política da urbanização, 14. ed. revista (1ª ed. em 1973). São Paulo, Contexto, 1998a.

Contexto, 1998b.

Globalização e desemprego: diagnóstico e alternativas. São Paulo,

Aprender economia. São Paulo, Contexto, 1999.

Para entender o mundo financeiro. São Paulo, Contexto, 2000a.

Economia socialista. In, SINGER, Paul \& MACHADO, João, Economia socialista. São Paulo, Ed. Fundação Perseu Abramo, 2000b.

Economia solidária: um modo de produção e distribuição. In: SINGER, Paul \& SOUZA, André R. de. A economia solidária no Brasil: a autogestão como resposta ao desemprego. São Paulo, Contexto, 2000c.

Alfredo Costa-Filho é economista (USP) e foi diretor-geral do Instituto Latino-americano e do Caribe de Planejamento Econômico e Social (ILPES-Nações Unidas, 1982-92). É consultor privado internacional. 